Research Paper

\title{
Prognostic role of metformin intake in diabetic patients with colorectal cancer: An updated qualitative evidence of cohort studies
}

\author{
Lili Du ${ }^{1, *}$, Mingli Wang ${ }^{1, *}$, Yingying Kang ${ }^{1, *}$, Bo $^{1}{ }^{1}$, Min Guo ${ }^{1}$, Zhifeng Cheng ${ }^{1}$, \\ Changlong $\mathbf{B i}^{1}$ \\ ${ }^{1}$ Department of Endocrinology, The Fourth Affiliated Hospital of Harbin Medical University, Harbin, China \\ *These authors have contributed equally to this work \\ Correspondence to: Changlong Bi, email: bcl_63@163.com \\ Zhifeng Cheng, email: zhifc55@126.com \\ Keywords: metformin, anti-diabetic drug, colorectal cancer, prognosis, diabetes mellitus \\ Received: October 29, $2016 \quad$ Accepted: December 29, $2016 \quad$ Published: January 17, 2017
}

Copyright: Du et al. This is an open-access article distributed under the terms of the Creative Commons Attribution License (CC-BY), which permits unrestricted use, distribution, and reproduction in any medium, provided the original author and source are credited

\section{ABSTRACT}

Several observational studies have shown that metformin can modify the risk and survival of colorectal cancer (CRC) in patients with diabetes mellitus, although the magnitude of this relationship has not been determined. We conducted an updated systematic review and meta-analysis to analyze the association between metformin and CRC mortality and searched relevant databases up to July 2016. The primary outcome was overall survival (OS). Secondary outcomes were cancer-specific survival (CS) and disease-free survival (DFS). Summary hazard ratios (HRs) were calculated using a random-effects model. Seventeen studies enrolling 269,417 participants were eligible for inclusion. Comparing with non-metformin users in diabetic CRC patients, the summary HRs for OS in metformin users were 0.69 (95\% CI, 0.61-0.77). Subgroup analyses stratified by the study characteristics and sensitivity analysis by the trimand-fill method (adjusted HR 0.77, 95\% CI, 0.67-0.87) confirmed the robustness of the results. However, significant OS benefit was noted in patients with stage II and III disease. Five studies reported the CRC prognosis for CS and three for DFS; metformin intake was significantly associated with patient CS (HR 0.75, 95\% CI, 0.59-0.94), but not DFS (HR 0.38, 95\% CI, 0.13-1.17). Our findings suggest that metformin intake is associated with improved survival outcomes in terms of OS and CS in CRC patients with diabetes, particular for OS in stage II and stage III patients. Further studies should be conducted to determine CRC survival between metformin use and patient specific clinical and molecular profiles.

\section{INTRODUCTION}

As a commonly used oral anti-hyperglycaemic agent for type 2 diabetes mellitus (DM), metformin can improve insulin sensitivity by increasing peripheral glucose intake and utilization [1]. It has also been indicated that insulin might play an important role in tumorigenesis. Numerous epidemiologic studies have reported that metformin is associated with decreased risk of cancer incidence [2-7]. Metformin is supposed to inhibit cellular growth and proliferation by lowering insulin levels through the phosphoinositide 3-kinase (PI3K)/protein kinase B (Akt)/ mammalian target of rapamycin (mTOR) pathway pathways $[8,9]$. Recent published study has also shown that metformin exhibits an anti-apoptotic effect on podocytes under high glucose conditions through activation of adenosine monophosphate-activated protein kinase (AMPK) and inhibition of mTOR signaling [10]. More and more researches have focused on the potential role of metformin as a combined drug for patients with cancer. Metformin intake has been reported to be associated with reduced risk of colorectal cancer (CRC) as well as improved survival in CRC patients [11-18], such as pathologic complete response in locally advanced rectal cancer treated 
with chemoradiotherapy [19]. Several meta-analyses have also examined the association between metformin and CRC survival [20, 21]. However, these systematic reviwews are quite preliminary with limited number of studies included and low statistical power to draw a definite conclusion. Moreover, the findings of previous meta-analyses were difficult to interprete due to heterogeneity in patient/ population selection, metformin exposure, outcome measures, and study design. During the last two years, several related large cohorts were studied and the results were published [13, 17, 22]. Therefore, there is an urgent need to conduct an updated meta-analysis to systematically renew the evidence about the association between metformin intake and survival outcomes in CRC patient with DM.

\section{RESULTS}

\section{Search and selection of studies}

Literature search generated a total of 616 citations, of which 43 appeared relevant through title/abstract selection and were retrieved for further full text evaluation (Figure 1). Finally, 17 studies met all eligibility criteria and were included in the meta-analysis [11-17, 19, 22-30] (Figure 1 and Supplementary Table 1).

\section{Study characteristics}

Seventeen observational studies with a total of 269,417 individuals were involved in the study. Eight took place in USA and Canada (North America), six in Asia and three in Europe. Ten studies recruited participants from multiple centers, while seven recruited exclusively from single centers. The median number of sample size per study was 3816 (range, 482-111673). Nine of the included studies were population-based cohort studies and eight were hospital-based cohort studies. Two studies enrolled patients with rectal cancer only, one study with only colon cancer, while the other studies included patients with both colon and rectal cancer. Thirteen of the seventeen studies examined patients with CRC of all stages (I-IV), while two studies enrolled only stage III and stage IV patients, respectively, and another reported I-III stage patients. Based on NOS criteria, out of nine possible points, five studies received nine points, three received eight points, three received seven points, two received six points, three received five point, and two received four points (Table 1).

Important baseline characteristics of the included studies in the meta-analysis are presented in Table 1. Seventeen studies investigated the association between metformin use and OS for CRC patients [11-17, 19, 22$30]$, whereas five $[13,14,16,22,24]$ and three $[19,29,31]$ studies reported the CS and DFS, respectively. Three and four studies contained survival data of exclusively colon and rectal cancer, respectively. However, the majority of the included studies involved both colon and rectal cancer patients. Patients with a mixture of stage I-IV disease was investigated in fourteen studies and four other studies included stage II, IV or I-III cancer patients. The

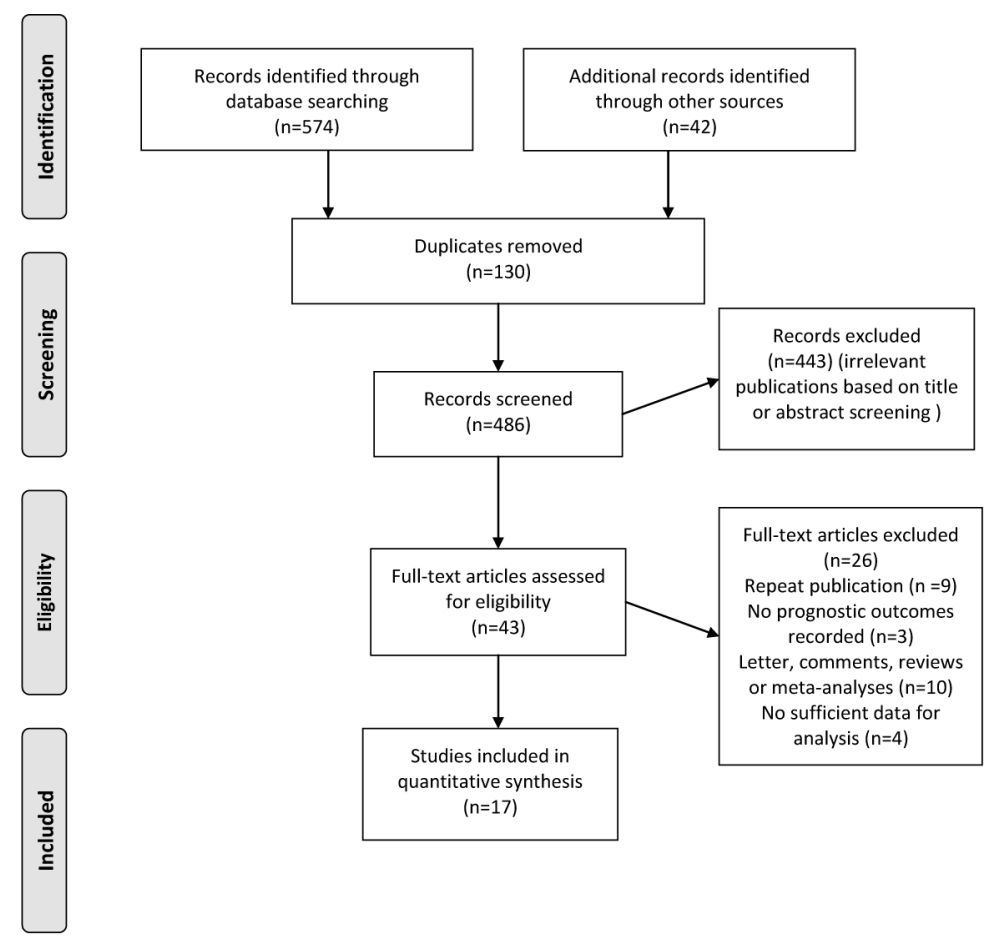

Figure 1: Flow diagram of selection of studies investigating effect of metformin intake on survival in patients with colorectal cancer. 
Table 1: Characteristics of the included studies on survival outcomes of metformin use and colorectal cancer survival

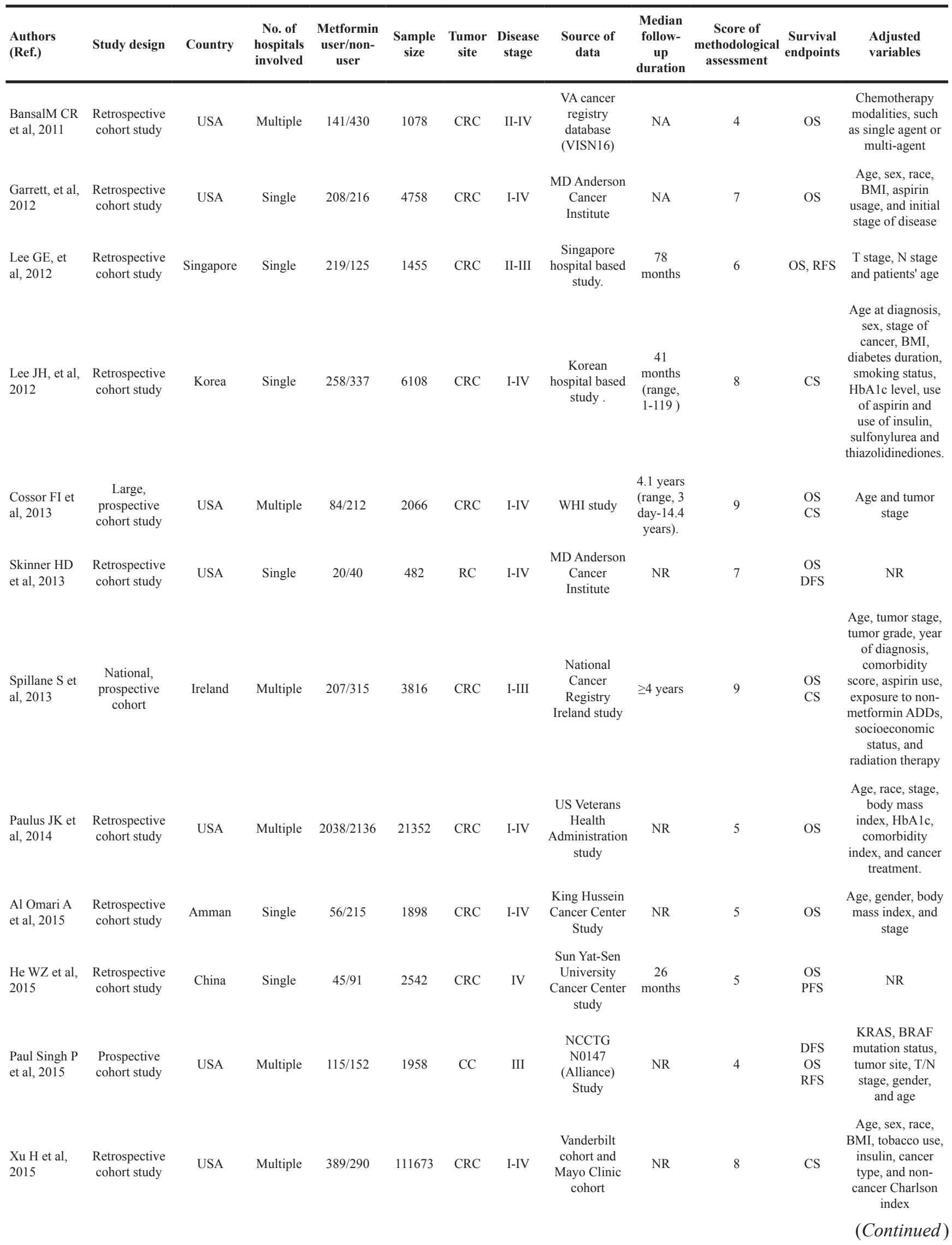




\begin{tabular}{|c|c|c|c|c|c|c|c|c|c|c|c|c|}
\hline $\begin{array}{l}\text { Authors } \\
\text { (Ref.) }\end{array}$ & Study design & Country & $\begin{array}{c}\text { No. of } \\
\text { hospitals } \\
\text { involved }\end{array}$ & $\begin{array}{l}\text { Metformin } \\
\text { user/non- } \\
\text { user }\end{array}$ & $\begin{array}{c}\text { Sample } \\
\text { size }\end{array}$ & $\begin{array}{l}\text { Tumor } \\
\text { site }\end{array}$ & $\begin{array}{l}\text { Disease } \\
\text { stage }\end{array}$ & $\begin{array}{c}\text { Source of } \\
\text { data }\end{array}$ & $\begin{array}{c}\text { Median } \\
\text { follow- } \\
\text { up } \\
\text { duration }\end{array}$ & $\begin{array}{c}\text { Score of } \\
\text { methodological } \\
\text { assessment }\end{array}$ & $\begin{array}{c}\text { Survival } \\
\text { endpoints }\end{array}$ & $\begin{array}{l}\text { Adjusted } \\
\text { variables }\end{array}$ \\
\hline $\begin{array}{l}\text { Zanders MM } \\
\text { et al, } 2015\end{array}$ & $\begin{array}{l}\text { Population- } \\
\text { based cohort } \\
\text { study }\end{array}$ & $\begin{array}{l}\text { The } \\
\text { Netherlands }\end{array}$ & Multiple & $666 / 377$ & 8725 & $\mathrm{CRC}$ & I-IV & $\begin{array}{c}\text { ECR- } \\
\text { PHARMO } \\
\text { cohort }\end{array}$ & $\begin{array}{l}3.4 \text { years } \\
\text { (s.d. } \pm 3.0 \text { ) }\end{array}$ & 9 & OS & $\begin{array}{l}\text { Sex, age at } \\
\text { CRC diagnosis, } \\
\text { calender year of } \\
\text { CRC diagnosis, } \\
\text { type of CRC, } \\
\text { stage at CRC } \\
\text { diagnosis and } \\
\text { administration } \\
\text { of surgery, } \\
\text { radiotherapy and/ } \\
\text { or chemotherapy, } \\
\text { use of other } \\
\text { diabetes } \\
\text { medication, } \\
\text { statins and aspirin }\end{array}$ \\
\hline $\begin{array}{l}\text { Fransgaard T } \\
\text { et al, } 2015\end{array}$ & $\begin{array}{l}\text { Population- } \\
\text { based cohort } \\
\text { study }\end{array}$ & Denmark & Multiple & $1962 / 1429$ & 30493 & $\mathrm{CRC}$ & I-IV & $\begin{array}{l}\text { Danish } \\
\text { Colorectal } \\
\text { Group's } \\
\text { National } \\
\text { Clinical } \\
\text { Database }\end{array}$ & NR & 7 & OS & $\begin{array}{l}\text { Age, sex, ASA } \\
\text { score, BMI, blood } \\
\text { transfusions, } \\
\text { smoking, alcohol } \\
\text { consumption, } \\
\text { elective or } \\
\text { emergency } \\
\text { surgery, type } \\
\text { of cancer, T } \\
\text { stage, lymph } \\
\text { node status, and } \\
\text { distant metastasis, } \\
\text { diabetic } \\
\text { complications }\end{array}$ \\
\hline $\begin{array}{l}\text { Ki YJ et al, } \\
2016\end{array}$ & $\begin{array}{l}\text { Population- } \\
\text { based } \\
\text { retrospective } \\
\text { cohort study }\end{array}$ & Korea & Multiple & $3649 / 809$ & 58124 & $\mathrm{RC}$ & I-IV & $\begin{array}{l}\text { Korea Center } \\
\text { Cancer } \\
\text { Registry study }\end{array}$ & NR & 8 & OS, CS & $\begin{array}{c}\text { Sex, age, SEER } \\
\text { stage, Charlson's } \\
\text { comorbidity } \\
\text { index score, } \\
\text { Preoperative } \\
\text { chemotherapy, } \\
\text { Adjuvant } \\
\text { chemotherapy }\end{array}$ \\
\hline $\begin{array}{l}\text { Mc Menamin } \\
\text { UC et al, } \\
2016\end{array}$ & $\begin{array}{l}\text { Retrospective } \\
\text { cohort study }\end{array}$ & $\begin{array}{l}\text { Northern } \\
\text { Ireland }\end{array}$ & Multiple & $675 / 552$ & 11595 & $\mathrm{CRC}$ & I-IV & $\begin{array}{l}\text { NCDR, } \\
\text { CPRD and } \\
\text { ONS death } \\
\text { registrations. }\end{array}$ & $\begin{array}{c}4 \text { years } \\
\text { ranged } \\
\text { from } 6 \\
\text { months } \\
\text { to } 14 \\
\text { years. }\end{array}$ & 9 & OS, CS & $\begin{array}{l}\text { Gender, year of } \\
\text { diagnosis, age } \\
\text { at diagnosis, } \\
\text { deprivation, } \\
\text { site, surgery } \\
\text { within } 6 \text { months, } \\
\text { radiotherapy } \\
\text { within } 6 \text { months, } \\
\text { chemotherapy } \\
\text { within } 6 \text { months, } \\
\text { comorbidities. } \\
\text { other anti-diabetic } \\
\text { medication } \\
\text { usage,and other } \\
\text { medication usage }\end{array}$ \\
\hline $\begin{array}{l}\text { Ramjeesingh } \\
\text { R et al, } 2016\end{array}$ & $\begin{array}{l}\text { Retrospective } \\
\text { cohort study }\end{array}$ & Canada & Single & $133 / 144$ & 1304 & $\mathrm{CRC}$ & I-IV & $\begin{array}{l}\text { The Cancer } \\
\text { Centre of } \\
\text { Southeastern } \\
\text { Ontario }\end{array}$ & NR & 6 & OS & $\begin{array}{c}\text { Age, sex, } \\
\text { comorbidities, } \\
\text { diabetes } \\
\text { treatments, BMI, } \\
\text { smoking history, } \\
\text { alcohol history, } \\
\text { family history } \\
\text { of crc, location } \\
\text { of cancer, stage } \\
\text { at diagnosis, } \\
\text { differentiation }\end{array}$ \\
\hline
\end{tabular}

Abbreviations: ADDs, anti-diabetic drugs; ASA, American Society of Anesthesiologists; BMI, body mass index;BRAF, BRAF mutation; CRC, colorectal cancer; CS, cancerspecific survival; DFS, disease-free survival; KRAS, KRAS mutation; N, N stage; NR, not reported; OS, overall survival; RFS, recurrence-free survival; SEER, the Surveillance, Epidemiology, and End Results; T, T stage. 
median follow-up period ranged from 26 months to more than four years from the available follow-up information. Age, gender, body mass index, and stage were four most commonly investigated variables that were adjusted for in Cox's proportional-hazard model evaluation of the association between metformin intake and CRC mortality.

\section{Metformin intake and CRC prognosis}

Meta-analysis based on all observational studies assessing CRC OS in patients with DM indicated that compared with non-use, metformin use was significant associated with decreased OS in patients with DM (HR 0.69, $95 \%$ CI 0.61-0.77, Figure 2), with considerable heterogeneity across studies $\left(\mathrm{I}^{2}=73.5 \%\right)$. The analysis of studies when involving prospective cohorts showed similar results with low heterogeneity (HR $0.83,95 \% \mathrm{CI}$ $0.75-0.92, \mathrm{I}^{2}=0 \%$ ).

Five studies reported the CRC prognosis for CS and three for DFS; metformin intake was significantly associated with patient CS (HR 0.75, 95\% CI, 0.59-0.94), but not DFS (HR 0.38, 95\% CI, 0.13-1.17).

\section{Subgroup analyses}

The effect of metformin use on patient OS appeared to be smaller among studies investigating only colon cancers (pooled HR 0.83, 95\% CI 0.67-1.03, three studies, $\mathrm{I}^{2}=0 \%$ ) compared with studies including only rectal cancers (HR 0.73, 95\% CI 0.58-0.91, four studies, $\mathrm{I}^{2}=41.4 \%$, Table 2 ). However, we did not note statistically significant difference between this subgroup ( $P$ for interaction $=0.40$ ).

The prognostic effect of metformin intake on patient OS was larger in studies that limited their analyses in retrospective studies (HR 0.63, 95\% CI 0.54-0.74, twelve studies, $\mathrm{I}^{2}=78.8 \%$ ) compared with the estimates from studies that limited their analyses in prospective studies (HR 0.83, 95\% CI 0.75-0.92, five studies, $\mathrm{I}^{2}=0 \%$ ). Significant subgroup difference was observed $(P$ for interaction $=0.004$ ).

The prognostic effect of metformin intake was also noted significantly large in the subgroup of patient origin from hospital-based studies (HR 0.56, 95\% CI 0.45-0.70, $\mathrm{I}^{2}=72.8 \%$; Table 2), compared with that from populationbased studies (HR $0.79,95 \%$ CI $0.72-0.88, \mathrm{I}^{2}=49.4 \%, P$ for interaction $=0.005$ ). Another possible interaction was noted in subgroup of different number of centers involved for OS $(P$ for interaction $=0.037)$.

Results of other subgroup analyses are presented in Table 2, which showed that the prognostic effect remained stable for patients with different research region, sample size and NOS score. When the analyses were limited to individual CRC tumor stage, we noted that statistical prognistic effect was noted only in stage II and stage III patients, but not in stage I and stage IV patients.

\section{Sensitivity analyses and publication bias}

For OS subset, the funnelplot indicated asymmetry and the presence of publication bias (Figure 3). The hollow circles showed that three missing studies that lay in the non-significant regions of the plot, suggesting that asymmetry was attributed partly to publication bias, which was further confirmed with Egger's linear regression test $(P=0.037)$. The adjusted random effects pooled HR of 0.77 (95\% CI, 0.67-0.87) calculated using the trim-andfill method remained constant with the original analysis. We did not explore the publication bias for CS or DFS due to the limited number of studies involved.

\section{DISCUSSION}

This meta-analysis based on patient survival data from observational studies comparing metformin use and non-use in patients with $\mathrm{CRC}$ revealed that metformin intake was associated with better outcomes in terms of OS and $\mathrm{CS}$.

The significant association between metformin intake and OS of patients was also noted in most baseline subsets, further confirming the prognostic role of metformin in CRC. However, the significant associations were exhibited in only rectal cancer patients and stage II and stage III patients, probably due to the limited number of studies involved.

A significant heterogeneity $\left(\mathrm{I}^{2}=73.5 \%\right)$ of the analysis was observed in this systematic review for OS. In sensitivity analysis, exclusion of each of the studies in turn did not largely alter the significance of the pooled estimate. Subgroup analysis showed that the heterogeneity significantly reduced for most investigated baseline characteristics (Table 2), indicating that the source of interstudy heterogeneity may partly attribute to these variables. Moreover, subgroup analysis indicated that metformin intake was significantly correlated with improved OS for CRC patients in stage II (HR 0.73; 95\% CI 0.57-0.93), stage III tumors (HR $0.5895 \%$ CI $0.37-0.92$ ) and rectal cancer (HR 0.73; 95\% CI 0.58-0.91), while not in other stages or in colon cancer. As the influential factors and characteristics of CRC in different locations and stages might differ because of diverse molecular profiles and epigenetic background of tumors, the prognosis of CRC might vary among different tumor locations and stages. However, though it did not reach statistical significance for some subsets, the trends all indicated that patients with metformin intake had favorable OS, probably due to the limited sample size or statistical power involved. More prospective and multicenter studies might further clarify its real prognostic role in specific cancer profiles.

The finding that stage II/III CRC patients who used metformin had more survial benefits than stage I/IV patients, which was consistent with the findings of some previously published studies $[12,14]$. We proposed 


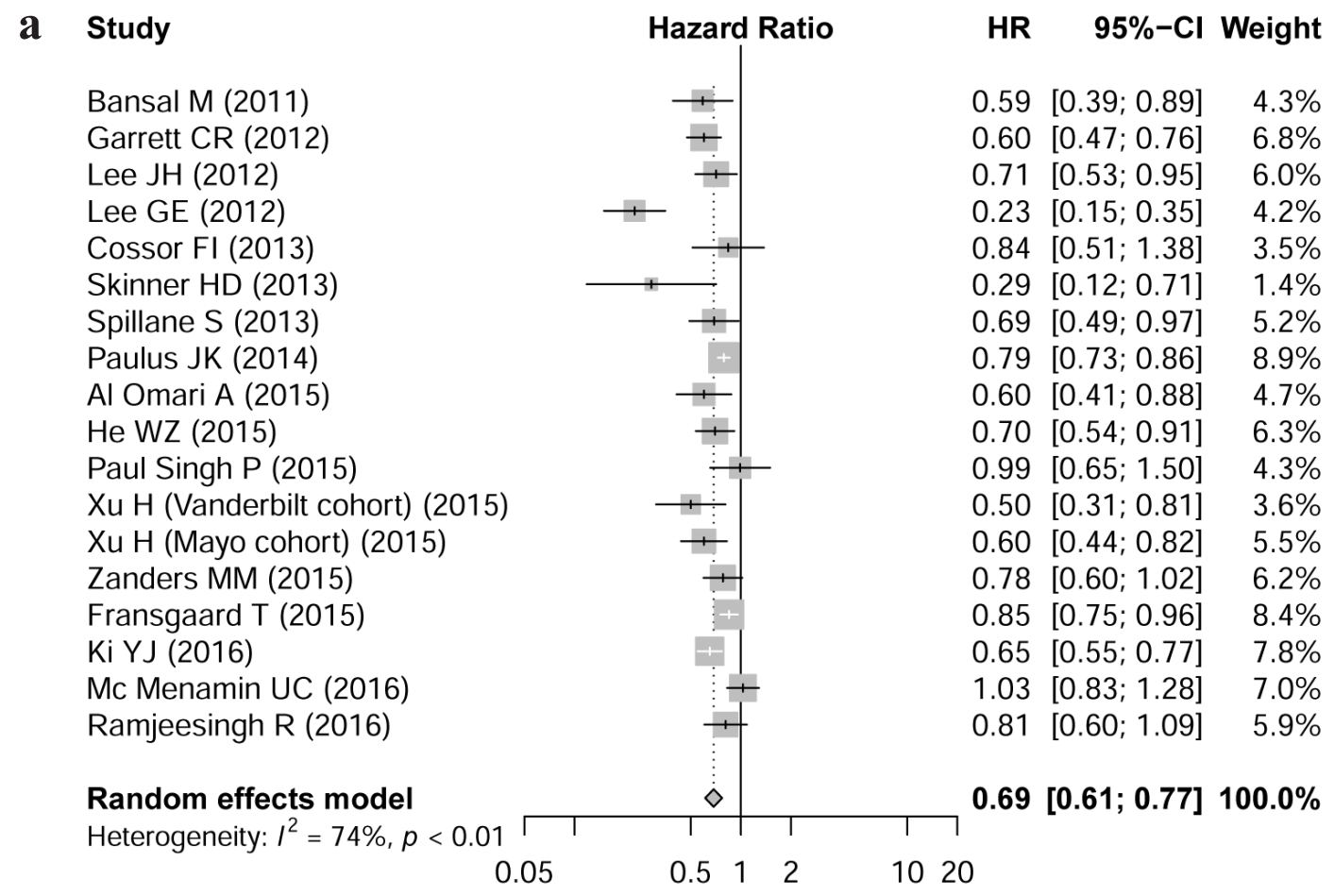

b

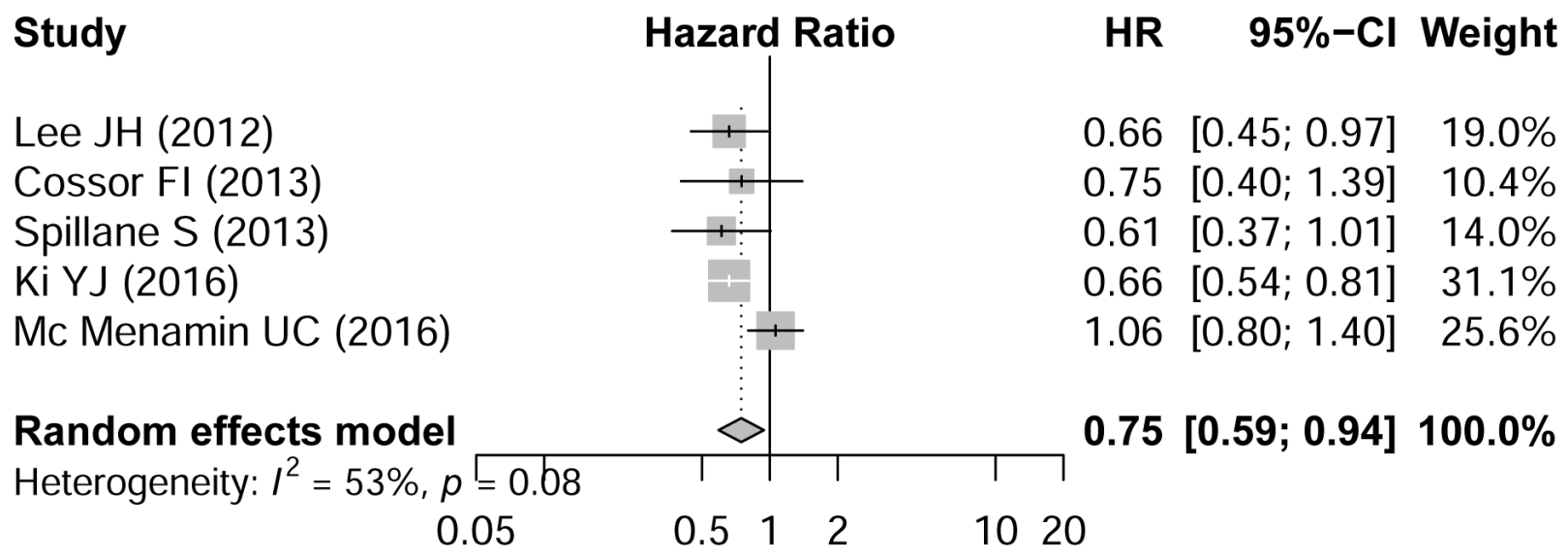

c

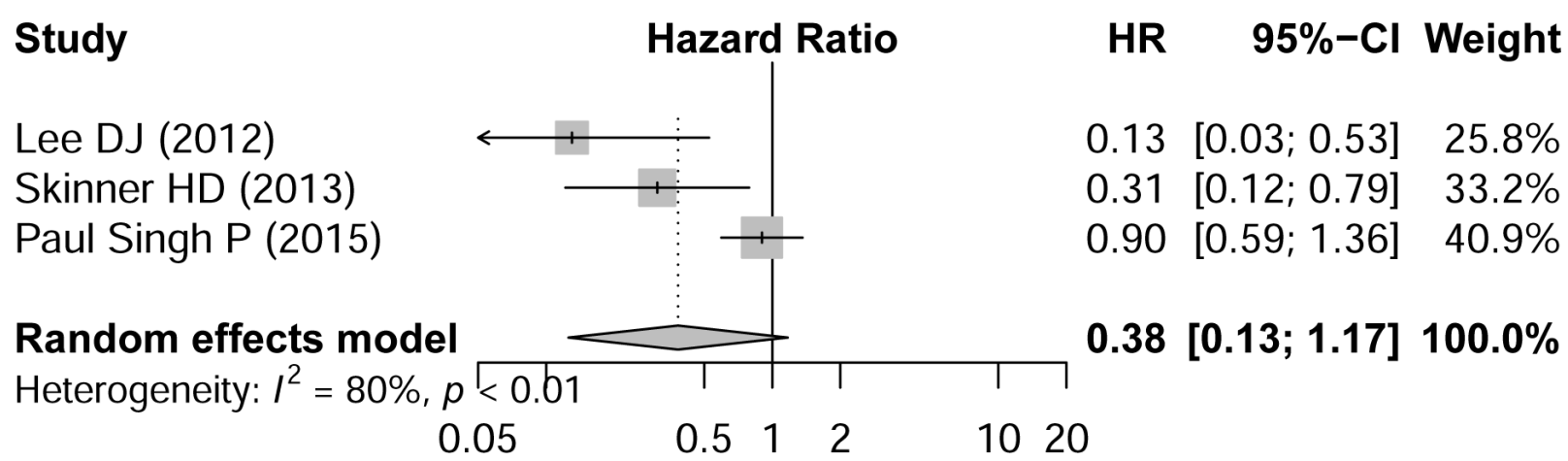

Figure 2: Hazard ratio for association between metformin intake and a. overall survival, b. cancer-specific survival, c. disease-free survival. Forest plots of 17 cohorts. Weights are from random effects analysis.

Abbreviations: CI, confidence interval; HR, hazard ratio; W (random): Weights (random effects model). 
Table 2: Subgroup analyses of the associations between metformin use and overall survival

\begin{tabular}{|c|c|c|c|}
\hline \multirow{2}{*}{ Comparison variables } & \multicolumn{3}{|c|}{ Overall survival } \\
\hline & $\mathrm{N}\left(\mathrm{I}^{2}\right.$ statistics $\left.\%, P_{\text {het }}\right)$ & HR 95\% CI & $\boldsymbol{P}_{\text {interaction }}$ \\
\hline Total & $17(73.5,<0.001)$ & $0.69[0.61 ; 0.77]$ & NA \\
\hline Study design & & & 0.004 \\
\hline Prospectively & $5(0,0.704)$ & $0.83[0.75 ; 0.92]$ & \\
\hline Retrospectively & $12(78.8,<0.001)$ & $0.63[0.54 ; 0.74]$ & \\
\hline Patient origin & & & 0.005 \\
\hline Population-based & $9(49.4,0.045)$ & $0.79[0.72 ; 0.88]$ & \\
\hline Hospital-based & $8(72.8,<0.001)$ & $0.56[0.45 ; 0.70]$ & \\
\hline Research country & & & 0.066 \\
\hline North America & $8(54.2,0.026)$ & $0.69[0.59 ; 0.80]$ & \\
\hline Europe & $3(0,0.048)$ & $0.82[0.74 ; 0.91]$ & \\
\hline Asia & $6(87.4,<0.001)$ & $0.62[0.45 ; 0.84]$ & \\
\hline Centers involved & & & 0.037 \\
\hline Single & $7(79.1,<0.001)$ & $0.56[0.42 ; 0.74]$ & \\
\hline Multiple & $10(54.9,0.014)$ & $0.76[0.69 ; 0.85]$ & \\
\hline Sample size & & & 0.923 \\
\hline$<5000$ & $9(25.2,0.220)$ & $0.69[0.60 ; 0.79]$ & \\
\hline$\geq 5000$ & $8(84.2,<0.001)$ & $0.68[0.57 ; 0.80]$ & \\
\hline NOS score & & & 0.102 \\
\hline$<7$ & $6(80.7,<0.001)$ & $0.76[0.69 ; 0.84]$ & \\
\hline$\geq 7$ & $11(11.2,0.344)$ & $0.64[0.54 ; 0.77]$ & \\
\hline Tumor location & & & 0.40 \\
\hline Colon & $3(0,0.392)$ & $0.83[0.67 ; 1.03]$ & \\
\hline Rectum & $4(41.4,0.172)$ & $0.73[0.58 ; 0.91]$ & \\
\hline Tumor stage & & & 0.367 \\
\hline Stage I & $2(0,0.936)$ & $0.98[0.47 ; 2.02]$ & \\
\hline Stage II & $2(0,0.921)$ & $0.73[0.57 ; 0.93]$ & \\
\hline Stage III & $3(0,0.882)$ & $0.58[0.37 ; 0.92]$ & \\
\hline Stage IV & $6(56.6,0.042)$ & $0.90[0.67 ; 1.20]$ & \\
\hline Stage I/II/III & $3(72.4,0.027)$ & $0.82[0.61 ; 1.10]$ & \\
\hline
\end{tabular}

Abbreviations: CI, confidence interval; het, heterogeneity; HR, hazard ratio; N, number of studies; NA, not available.

that some of the stage II and almost all of the stage III patients would receive adjuvant chemotherapy, which played an important role in the clinical outcomes of these patients. Therefore, we suggested that metformin had a potential synergic effect with other anti-cancer agents and might be a candidate drug as an additional therapy to adjuvant chemotherapy in stage II/III CRC (locally advanced CRC). However, limited sample size were included and caution should be taken when when interpreting these results.

Several explanations for the potential association between metformin intake and CRC patient survival were proposed. It was reported that metformin enhanced tumor necrosis factor-related apoptosis-inducing ligandinduced apoptosis through the degradation of myeloid cell leukemia-1 (MCL-1) by the proteasome machinery 
[32]. Metformin has also an inhibitory effect on cell proliferation mediated by suppression of mTOR and insulin-like growth factor 1 (IGF1)/AKT pathways [33]. In addition, Langer et al.has found that metformin can increase cell viability which was associated with reduced apoptosis. This factor is also associated with increased AMPK and Akt or reduced mTOR in a concentrationdependent manner, thus mediating pro-survival effects after apoptosis-inducing high glucose stimulation [10]. Still, previous research has also suggested that the biologic effects of metformin are mediated through reexpression of miRNAs and decreased expression of cancer stem cellspecific genes, indicating that metformin is beneficial for overcoming therapeutic resistance of certain cancer cells [34].

For subset of OS, significant between-study heterogeneity was noted $\left(\mathrm{I}^{2}=73.5 \%, P_{\text {heterogeneity }}<0.001\right)$. The result of sensitivity analyses showed that exclusion any one of the study did not greatly change the pooled estimate. The results of the trim-and-fill method and subgroup analyses stratified by the major clinical variables had the same trend with the main analyses, indicating the robustness of our findings which were not influenced by publication bias. However, still caution should be taken when interpreting the findings, as publication bias is unavoidable and the statistical analyses for publication bias are not perfectly comprehensive.

Three previous meta-analyses have examined metformin intake for predicting CRC patient survival $[20,21,35]$. The first two meta-analyses by Mei et al and Zhang et al found that CRC patients with type $2 \mathrm{DM}$ who took metformin had longer OS and CS based on six and five cohort studies, respectively, which was reported again by $\mathrm{He}$ et al in 2016. However, due to the limited number of studies and small sample size, no sufficient statistical power of these two systmatic reviews has been added, so updated evidence is urgently needed for further clarify this associations.

This meta-analysis is the most comprehensive summary to provide robust statistical evidence for the substantial prognostic impact of metformin intake in CRC patients with type $2 \mathrm{DM}$. Despite the fact that several recently published studies showed a positive association between metformin and survival in CRC patients [11-15, 17, 19], the small sample size (ranging from 67 to 616) could not provide sufficient statistical power to draw a definite conclusion. These inconsistent findings could result from several factors. Firstly, the included studies had different study designs. Eight studies applied a convenience sample from single centers while other nine studies selected cases from multiple institutions. Nine studies used population-based cohorts while eight used hospital-based cohorts in epidemiologic settings. These variations would inevitably invlolve in selection bias. Secondly, the included studies covered a wide range of sample sizes from 106 to 111673 . We known that smaller studies in a meta-analysis could show larger treatment effects, leading to inaccurate estimates of effect sizes for the investigated association, and publication bias are very likely to occur. Asymmetry was clearly noted in the funnel plot (Figure 3). However, we used the trim-and-fill model for adjustment, and the result agreed with the primary

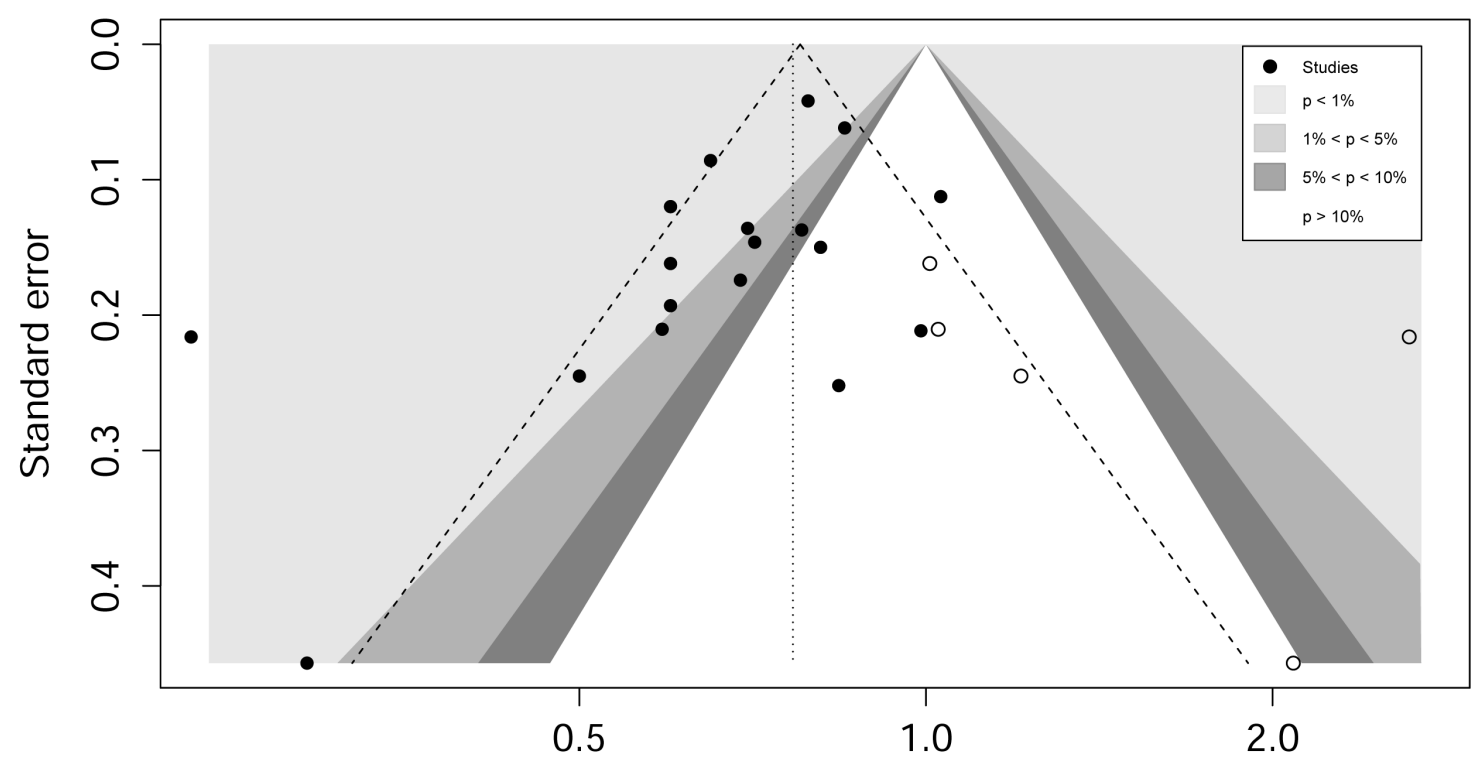

Hazard Ratio

Figure 3: Contour enhanced funnel plot for meta-analysis of the association between metformin intake and overall survival. The plots indicates that most studies were in the significant areas where $\mathrm{P}<0.01$ and where $0.01<\mathrm{P}<0.05$, while few studies were in the non-significant area (the blank area). Circles refer to included studies, and four missing studies (white circles) were filled. 
analysis, suggesting the significant association between metformin intake and CRC patient survival. Thirdly, the included studies involved various disease characteristics including tumor stage, location and other molecular features, which were other sources of heterogeneity. Our subgroup analyses have shown that metformin intake was significantly associated with patient OS only in stage II, stage III patients and rectal cancer patients, but not in stage I, stage IV patients or colon cancer patients. Nevertheless, these effects should be interpreted with caution due to limited studies in each studies and lack of sufficient statitical power. The findings of these subgroups should be further validated from more large-scale cohorts.

Limitations of this systematic review should not be ignored. Firstly, most of the studies did not have the information of the molecular date concerning KRAS, BRAF, PIK3CA mutation or microsatellite status, patient information of each tumor stage, chemotherapy or radiotherapy patient received, so sensitivity analyses could not be performed based on these variables. Secondly, as the included ones were all study-level studies, we could not abstract more detailed information of each individual, for example, duration and doses of metformin use, the stage of diabetes, concentration of blood glucose, and the amount of metformin intake for each people, etc, thus some of the subgroup analyses we were interested in could not be performed. Thirdly, the heterogeneity of statistical analyses lies in the difference in the adjustment variables among studies, which could have affected the accuracy and precision of the combined estimates. Multivariate Cox proportional hazards models were used in almost all of the studies except two $[13,19]$ that did not directly report survival estimates. We calculated the survival estimates using the method provided by Parmar et al. [36], by which uncertain bias, such as immortal time bias, for pooled estimates could have occured. Recently, it has been criticized that the effect of metformin on cancer survival might be exaggerated due to immortal time bias. However, some study showed that the presence of immortal time bias would not change the direction of metformin's effect on lung cancer [37]. We did sensitivity analysis by excluding studies that did not used multivariate Cox proportional hazards models and the direction of the result remained unchanged. Fourthly, we did not search unpublished gray literature, which could have led to publication bias.

Our study has several strengths. First, we thoroughly searched the four major databases without language or publication date limits, minimizing the risk of missing publications which might cause publication bias. Second, this meta-analysis is the largest and most comprehensive, including the biggest sample size of over 269,000 individuals, providing the solidest evidence for this topic currently. Third, we had done thorough stratified analysis based on some of the major study characteristics, such as the study design, participant features, follow-up period and NOS scale for study quality, and the findings were generally constant independent of some of the study characteristics. Fourth, we selected and cross-checked the identified studies, developed and abstracted the data, rated the study quality at least by two to three independent reviewers, minimizing the selection bias to the greatest extent and more objectively performing the systematic review.

In summary, our findings suggest that meformin intake is associated with improved survival outcomes in terms of OS and CS in CRC patients with DM, particular for OS in stage II and stage III patients. Further studies should be conducted to determine CRC survival between metformin use and patient specific clinical and molecular profiles.

\section{MATERIALS AND METHODS}

\section{Search strategy}

A literature search of the major databases including PubMed, Embase, the Cochrane Library Central Register of Controlled Trials and American Society of Clinical Oncology (ASCO) databases from inception to July 2016 was performed for all relevant studies investigating an association between metformin use and CRC prognostic outcomes. Supplementary Table 2-5 present the detailed search strategies using the following freetext words combined with Medical Subject Headings (MeSH) or EMTREE terms: "colorect*/colon*/rectum/ rectal", "cancer*/tumor*/tumour*/carcinom*/neoplas* / adenocarcinoma*/malignan*", "metformin/biguanide*", and "prognos*/survival/recurren*/mortality/predict*/ outcome*/death". Manual reference search was also conducted for recent citations in some of the high impact journals such as Annals of Oncology, Diseases of the Colon \& Rectum and the Journal of the National Cancer Institute. We also scrutinized for additional citations from the references of primary selected studies, reviews or meta-analyses which were not identified through database search. We did not apply date or language restrictions to our search strategy.

\section{Study selection and inclusion criteria}

Three reviewers (LD, MW and YK) independently evaluated all the titles and abstracts identified through the primary literature search, then selected and identified all the potentially relevant citations retrieved for full text reviews to assess for eligibility. Any disagreements were resolved by consensus or by a senior reviewer (CB or ZC) if necessary.

Observational studies were considered eligible for inclusion if: (1) studies published with original data in peer-review journals or published in style of abstracts without language restrictions; (2) studies at least reporting one of the survival outcomes, such as overall survival 
(OS), cancer-specific survival (CS) and disease-free survival (DFS); and (3) studies investigating the impact of metformin intake in CRC patients and providing prognostic data with a hazard ratio (HR) estimate and its 95\% confidence interval (CI) comparing survival outcomes of metformin users with that of in non-users. We excluded the following studies if: (1) studies containing no prognostic data; (2) studies having no sufficient information concerning prognostic parameters for analysis; and (3) study type including letters, comments or reviews without original data.

When duplicate publication suspected, we used the study with the largest sample size or contacted the corresponding authors and asked for clarification via e-mail if possible.

A comprehensive data abstraction form for each study containing the following baseline characteristics were extracted: the first author name, study design, research country, number of hospitals involved in the research, number of patients taking metformin and not taking metformin, the sample size of the full cohort, tumor site, disease stage, source of data, median follow-up duration, survival outcomes with their estimates (HRs with corresponding 95\% CIs) and adjusted variables.

We used the 9-star Newcastle-Ottawa Scale (NOS) [38] to evaluate study quality, which was a validated tool for the assessment of the methodological quality of nonrandomized studies. Three domains including selection of the participants, comparability of the participants and outcomes were allocated to 9 points. We proposed a score of more than 6 as high risk of bias.

\section{Statistical analysis}

Data analysis was synthesized using $\mathrm{R}$ software version 3.1.2. and Stata ${ }^{\circledR}$ version 12.0 (StataCorp LP, College Station, Texas, USA). We expressed time-to event data as HRs with 95\% CIs. Between-study heterogeneity was tested using $\mathrm{I}^{2}$ statistic defined as an $\mathrm{I}^{2}$ value $>50 \%$ indicating substantial heterogeneity. As substantial clinical, methodological, or statistical heterogeneity among included studies, we pooled the data using a random-effects model for the meta-analysis or using the method reported by Parmar et al [36]. We investigated the source of heterogeneity through subgroup analyses by examining potential influencial variables that could explain some of the heterogeneity. Differences between subgroups were evaluated using the test of subgroup differences described by Deeks et al [39]. Publication bias was assessed by visual inspection of the funnel plot symmetry combined with Begg's regression or Egger's linear regression method $[40,41]$, with a $P$ value less than 0.05 indicating statistically significant. We also tested the possible impact of publication bias through Duval's nonparametric trim-and-fill method [42].

\section{ACKNOWLEDGMENTS}

Study concept and design (ZC CB);

Acquisition of data (LD MW YK);

ZC CB);

Analysis and interpretation of data (LD MW YK

Drafting of the manuscript (LD MW CB);

Critical revision of the manuscript for important

intellectual content (LD MW YK ZC CB);

Obtained funding (ZC CB);

Study supervision (ZC CB).

\section{CONFLICTS OF INTEREST}

The authors declare no competing financial interests.

\section{GRANT SUPPORT}

This research was supported by Science Fund of Heilongiiang Province (grant no. H2016020), the Foundation of the Health and Family Planning Commission Research Project of Heilongjiang Province (grant no. 2014-390), Excellent Youth Foundation of the Fourth Affiliated Hospital of Harbin Medical University (grant no. HYDSYJQ201502).

\section{REFERENCES}

1. Group TS. Effects of metformin, metformin plus rosiglitazone, and metformin plus lifestyle on insulin sensitivity and beta-cell function in TODAY. Diabetes care. 2013; 36:1749-1757.

2. Bodmer M, Becker C, Jick SS, Meier CR. Metformin does not alter the risk of lung cancer: a case-control analysis. Lung cancer. 2012; 78:133-137.

3. Bodmer M, Becker C, Meier C, Jick SS, Meier CR. Use of metformin is not associated with a decreased risk of colorectal cancer: a case-control analysis. Cancer Epidemiol Biomarkers Prev. 2012; 21:280-286.

4. Chlebowski RT, McTiernan A, Wactawski-Wende J, Manson JE, Aragaki AK, Rohan T, Ipp E, Kaklamani VG, Vitolins M, Wallace R, Gunter M, Phillips LS, Strickler H, et al. Diabetes, metformin, and breast cancer in postmenopausal women. J Clin Oncol. 2012; 30:2844-2852.

5. Currie CJ, Poole CD, Gale EA. The influence of glucoselowering therapies on cancer risk in type 2 diabetes. Diabetologia. 2009; 52:1766-1777.

6. Li D, Yeung SC, Hassan MM, Konopleva M, Abbruzzese JL. Antidiabetic therapies affect risk of pancreatic cancer. Gastroenterology. 2009; 137:482-488.

7. Libby G, Donnelly LA, Donnan PT, Alessi DR, Morris AD, Evans JM. New users of metformin are at low risk of incident cancer: a cohort study among people with type 2 diabetes. Diabetes Care. 2009; 32:1620-1625. 
8. Bennett WL, Keeton AB, Ji S, Xu J, Messina JL. Insulin regulation of growth hormone receptor gene expression: involvement of both the PI-3 kinase and MEK/ERK signaling pathways. Endocrine. 2007; 32:219-226.

9. Xu J, Keeton AB, Franklin JL, Li X, Venable DY, Frank SJ, Messina JL. Insulin enhances growth hormone induction of the MEK/ERK signaling pathway. J Biol Chem. 2006; 281:982-992.

10. Langer S, Kreutz R, Eisenreich A. Metformin modulates apoptosis and cell signaling of human podocytes under high glucose conditions. J Nephrol. 29:765-773.

11. Fransgaard T, Thygesen LC, Gogenur I. Metformin Increases Overall Survival in Patients with Diabetes Undergoing Surgery for Colorectal Cancer. Ann Surg Oncol. 2016; 23:1569-1575.

12. Garrett CR, Hassabo HM, Bhadkamkar NA, Wen S, Baladandayuthapani V, Kee BK, Eng C, Hassan MM. Survival advantage observed with the use of metformin in patients with type II diabetes and colorectal cancer. Br J Cancer. 2012; 106:1374-1378.

13. Ki YJ, Kim HJ, Kim MS, Park CM, Ko MJ, Seo YS, Moon SM, Choi JA. Association Between Metformin Use and Survival In Non-Metastatic Rectal Cancer Treated with a Curative Resection: A Nationwide Population Study. Cancer Res Treat. 2016.128.

14. Lee JH, Kim TI, Jeon SM, Hong SP, Cheon JH, Kim WH. The effects of metformin on the survival of colorectal cancer patients with diabetes mellitus. Int J Cancer. 2012; 131:752-759.

15. Ramjeesingh R, Orr C, Bricks CS, Hopman WM, Hammad N. A retrospective study on the role of diabetes and metformin in colorectal cancer disease survival. Curr Oncol. 2016; 23:e116-122.

16. Spillane S, Bennett K, Sharp L, Barron TI. A cohort study of metformin exposure and survival in patients with stage I-III colorectal cancer. Cancer Epidemiol Biomarkers Prev. $2013 ; 22: 1364-1373$.

17. Xu H, Aldrich MC, Chen Q, Liu H, Peterson NB, Dai Q, Levy M, Shah A, Han X, Ruan X, Jiang M, Li Y, Julien JS, et al. Validating drug repurposing signals using electronic health records: a case study of metformin associated with reduced cancer mortality. J Am Med Inform Assoc. 2015; 22:179-191.

18. Zhang ZJ, Zheng ZJ, Kan H, Song Y, Cui W, Zhao G, Kip KE. Reduced risk of colorectal cancer with metformin therapy in patients with type 2 diabetes: a meta-analysis. Diabetes Care. 2011;34:2323-2328.

19. Skinner HD, Crane CH, Garrett CR, Eng C, Chang GJ, Skibber JM, Rodriguez-Bigas MA, Kelly P, Sandulache VC, Delclos ME, Krishnan S, Das P. Metformin use and improved response to therapy in rectal cancer. Cancer Med. 2013; 2:99-107.

20. He XK, Su TT, Si JM, Sun LM. Metformin Is Associated With Slightly Reduced Risk of Colorectal Cancer and
Moderate Survival Benefits in Diabetes Mellitus: A MetaAnalysis. Medicine. 2016; 95:e2749.

21. Mei ZB, Zhang ZJ, Liu CY, Liu Y, Cui A, Liang ZL, Wang $\mathrm{GH}$, Cui L. Survival benefits of metformin for colorectal cancer patients with diabetes: a systematic review and metaanalysis. PloS One. 2014; 9:e91818.

22. Mc Menamin UC, Murray LJ, Hughes CM, Cardwell CR. Metformin use and survival after colorectal cancer: A population-based cohort study. Int J Cancer. 2016; 138:369-379.

23. Bansal M, Siegel E, Govindarajan R. The effect of metformin (M) on overall survival (OS) of patients (Pts) with colorectal cancer (CRC) treated with chemotherapy (CTX). J Clin Oncol. 2011; 29.

24. Lee GE, Aung T, Lim KH, Tan WS, Tai WMD, Suhaimi $\mathrm{NAB}$, Tan MH, Tan IB. Examining the effects of metformin on survival outcome in stage II/III colorectal cancer patients with diabetes mellitus. J Clin Oncol. 2012; 30.

25. Cossor FI, Adams-Campbell LL, Chlebowski RT, Gunter MJ, Johnson K, Martell RE, McTiernan A, Simon MS, Rohan T, Wallace RB, Paulus JK. Diabetes, metformin use, and colorectal cancer survival in postmenopausal women. Cancer Epidemiol. 2013; 37:742-749.

26. Paulus JK, Cossor FI, Williams CD, Martell RE, Kelley MJ. Metformin (M), diabetes (DM), and colorectal cancer (CRC) survival among U.S. Veterans. J Clin Oncol. 2014; 32.

27. Al Omari A, Abdelkaleq H, Al-Hussaini M, Turfa R, Awad N, Hassan M, Garrett CR. The metformin effect on survival in Middle Eastern patients (pts) with type II diabetes (DM) and colorectal cancer (CRC). J Clin Oncol. 2015; 33.

28. He WZ, Xia LP. Impact of metformin on survival in patients with type II diabetes and metastatic colorectal cancer. J Clin Oncol. 2015; 33.

29. Paul Singh P, Shi Q, Foster NR, Grothey A, Nair S, Chan E, Shields AF, Goldberg RM, Gill S, Kahlenberg MS, Sinicrope FA, Sargent DJ, Alberts SR. Relationship between metformin use and recurrence and survival in patients (pts) with resected stage III colon cancer (CC) receiving adjuvant chemotherapy: Results from NCCTG N0147 (Alliance). J Clin Oncol. 2015; 33.

30. Zanders MM, van Herk-Sukel MP, Vissers PA, Herings RM, Haak HR, van de Poll-Franse LV. Are metformin, statin and aspirin use still associated with overall mortality among colorectal cancer patients with diabetes if adjusted for one another? E Br J Cancer. 2015; 113:403-410.

31. Lee DJ, Kim B, Lee JH, Park SJ, Hong SP, Cheon JH, Kim TI, Kim WH. The effect of metformin on responses to chemotherapy and survival in stage IV colorectal cancer with diabetes. Korean J Gastroenterol. 2012; 60:355-361.

32. Park SH, Lee DH, Kim JL, Lee SI, Kim BR, Na YJ, Lee SY, Kim HJ, Joung SY, Kang S. Metformin enhances TRAIL-induced apoptosis by Mcl-1 degradation via Mule in colorectal cancer cells. Cancer Res. 2016; 76:3497-3497. 
33. Mogavero A, Maiorana MV, Bertan C, Bozzi F, Pierotti MA, Gariboldi M. Metformin has an inhibitory effect on cell proliferation but does not induce death in colorectal cancer. Cancer Res. 2015; 75:1161-1161.

34. Bao B, Wang Z, Ali S, Ahmad A, Azmi AS, Sarkar SH, Banerjee S, Kong D, Li Y, Thakur S. Metformin inhibits cell proliferation, migration and invasion by attenuating CSC function mediated by deregulating miRNAs in pancreatic cancer cells. Cancer Prev Res (Phila). 2012; 5:355-364.

35. Zhang $\mathrm{ZJ}, \mathrm{Li} \mathrm{S}$. The prognostic value of metformin for cancer patients with concurrent diabetes: a systematic review and meta-analysis. Diabetes Obes Metab. 2014;16:707-710.

36. Parmar MK, Torri V, Stewart L. Extracting summary statistics to perform meta-analyses of the published literature for survival endpoints. Stat Med. 1998; 17:2815-2834.

37. Zhang ZJ, Bi Y, Li S, Zhang Q, Zhao G, Guo Y, Song Q. Reduced risk of lung cancer with metformin therapy in diabetic patients: a systematic review and meta-analysis. Am J Epidemiol. 2014;180:11-14.
38. Stang A. Critical evaluation of the Newcastle-Ottawa scale for the assessment of the quality of non-randomized studies in meta-analyses. Eur J Epidemiol. 2010; 25:603-605.

39. Deeks JJ, Altman DG, Bradburn MJ. Statistical methods for examining heterogeneity and combining results from several studies in meta-analysis. Systematic Reviews in Health Care: Meta-Analysis in Context, Second Edition. 2008:285-312.

40. Begg CB, Mazumdar M. Operating characteristics of a rank correlation test for publication bias. Biometrics. 50:1088-1101.

41. Egger M, Smith GD, Schneider M, Minder C. Bias in metaanalysis detected by a simple, graphical test. BMJ. 1997; 315:629-634.

42. Duval S, Tweedie R. Trim and fill: a simple funnel-plotbased method of testing and adjusting for publication bias in meta-analysis. Biometrics. 2000; 56:455-463. 